\title{
A PRODUÇÃO DO CONHECIMENTO RELATIVA AO ULTIMATE FRISBEE NO DECÊNIO 2009-2019
}

\author{
THE KNOWLEDGE PRODUCTION RELATIVE TO ULTIMATE FRISBEE IN \\ THE DECADE 2009-2019
}

\section{LA PRODUCCIÓN DE CONOCIMIENTO RELATIVA A ULTIMATE FRISBEE EN LA DÉCADA 2009-2019}

\author{
Angélica de Souza Silva \\ https://orcid.org/0000-0002-7850-460X (DD \\ http://lattes.cnpq.br/3601203396480249 9 \\ Universidade Federal de Lavras (Lavras, MG - Brasil) \\ angelica.silva2@estudante.ufla.br \\ Kleber Tüxen Carneiro \\ http://orcid.org/0000-0003-0826-6172 (ib \\ http://lattes.cnpq.br/7710578170809604 \\ Universidade Federal de Lavras (Lavras, MG - Brasil) \\ kleber2910@gmail.com
}

\begin{abstract}
Resumo
O artigo trata de apresentar uma revisão literária sistemática, cujo objetivo central consistiu em mapear artigos publicados em periódicos nacionais, dedicados ao entendimento do Frisbee, no interstício temporal de 2009 a 2019. A pesquisa se assentou numa perspectiva qualiquantitativa. Para formular as categorias de análises, empregamos os pressupostos da homogeneidade interna, heterogeneidade externa, inclusividade e plausividade, somado ao princípio de análise inferencial, de maneira a possibilitar tanto à elaboração das categorias de análise quanto subsidiar ilações relativas às produções mapeadas. Após o emprego de todo o delineamento metodológico, constatou-se o total de 52 revistas, considerando todas as estratificações na subárea da Educação Física, com efeito, constatou-se três artigos atinentes ao Ultimate Frisbee. Os mesmos foram analisados no interior de três categorias analíticas, quais sejam: Participação; Sistematização Pedagógica e Gênero. Em linhas gerais, o que fica patente a luz de nossa investigação é a tendência de aumento no somatório das produções, a julgar o decênio cotejado, muito embora tenha havido uma quantidade equitativa nos últimos três anos.
\end{abstract}

Palavras-chave: Ultimate Frisbee; Revisão de Literatura Sistemática; Educação Física.

\begin{abstract}
This is an article in which a systematic literature review study is presented, whose central objective was to map articles published in national journals, dedicated to the understanding of Frisbee, in the temporal interstice from 2009 to 2019. The research was based on a perspective qualiquantitative. To formulate the categories of analysis, we used the assumptions of internal homogeneity, external heterogeneity, inclusiveness and plausibility, added to the principle of inferential analysis, in order to enable both the elaboration of the analysis categories and subsidize lessons related to the mapped productions. After using the entire methodological design, a total of 52 magazines were found, considering all stratifications in the sub-area of Physical Education, in fact, 3 articles related to Ultimate Frisbee were contacted. They were analyzed within three analytical categories, namely: Participation; Pedagogical Systematization and Gender. In general, what is evident in the light of our investigation is a tendency to increase the sum of the productions, judging from the decade compared, even though there has been a fair amount in the last three years.
\end{abstract}

Keywords: Ultimate Frisbee; Systematic Literature Review; Physical Education.

\section{Resumen}


Se trata de un artículo en el que se presenta un estudio de revisión sistemática de la literatura, cuyo objetivo central fue mapear artículos publicados en revistas nacionales, dedicados a la comprensión del Frisbee, en el intersticio temporal de 2009 a 2019. La investigación se basó en una perspectiva cualitativa. Para formular las categorías de análisis se utilizaron los supuestos de homogeneidad interna, heterogeneidad externa, inclusividad y plausibilidad, sumados al principio de análisis inferencial, con el fin de posibilitar tanto la elaboración de las categorías de análisis como subsidiar lecciones relacionadas con las producciones mapeadas. Luego de utilizar todo el diseño metodológico, se encontraron un total de 52 revistas, considerando todas las estratificaciones en el sub-área de Educación Física, de hecho, se contactaron 3 artículos relacionados con Ultimate Frisbee. Fueron analizados dentro de tres categorías analíticas, a saber: Participación; Sistematización pedagógica y género. En general, lo que se evidencia a la luz de nuestra investigación es una tendencia a incrementar la suma de las producciones, a juzgar por la década comparada, a pesar de que ha habido una cantidad igual en los últimos tres años.

Palabras clave: Ultimate Frisbee; Revisión Sistemática de la Literatura; Educación Física.

\section{INTRODUÇÃO}

A palavra Frisbee, a rigor, não apresenta tradução literal, contudo faz referência, quando trazida à tona, a um disco de plástico côncavo projetado para deslizar pelo ar. Outras práticas esportivas utilizam-se de um disco, a exemplo do Beach Ultimate, o Disc Golf, o Freestyle, o Guts, o Double Disc Court (DDC), o Discathon e o Overall. No entanto, limitar-nosemos a tratar do Ultimate Frisbee.

Há diversos argumentos explicativos relativos ao surgimento do disco (frisbee), artefato principal do Ultimate Frisbee. Tal qual a diversidade de explicações, têm-se as divergências em relação às datas de eclosão, uma espécie de dissenso historiográfico, todavia a mais comumente admitida e disseminada, em consonância às informações do órgão regulador, remonta ao ano de 1871 no estado Connecticut, mais especificamente em Bridgeport, quando William Russell Frisbie (1848-1903) se tornou dono de uma padaria chamada "Frisbie Pie", que foi passada após sua morte a Joseph, seu filho. Com efeito, o pequeno negócio se converteu em um centro de distribuição de tortas para 250 locais americanos. E os frequentadores do referido centro, mais especificamente os estudantes da Universidade de Yale, divertiam-se lançando e recepcionando no ar as "formas" vazias de tortas, o que por sua vez "viralizou" entre o público jovem, com isso insurgem as primeiras versões dos discos de plástico para prática de Ultimate Frisbee. O primeiro deles foi criado por Fred Morrison em 1951, chamado "Pluto Platter" apresentando melhor estabilidade e consequentemente maior alcance de deslocamento, em comparação às formas de torta. A criação desse primeiro disco conduziu a venda da ideia e produção em massa de um disco por Wham-0 em 1955, uma conhecida fábrica de brinquedos (PUCCINELLI, 2006). 
Em 1968 ocorre o primeiro registro competitivo relativo ao Ultimate Frisbee, numa disputa entre o conselho estudantil e a equipe de funcionários do jornal da escola Columbia High School. A partir daí, a modalidade foi se disseminando por intermédio de torneios intercolegiais e interfaculdades até ao campeonato mundial, por efeito os esportes de disco começaram a ganhar adeptos pelo mundo (PUCCINELLI, 2006). No Brasil surge no final da década de 1980, com grande inserção em São Paulo/SP (BORGES et al., 2017).

Além dos atributos da competitividade esportiva, a referida prática corporal apresenta grande potencial educativo, devido a quatro predicados principais, quais sejam: o baixo nível de contato entre os oponentes; a organização tática que destaca o jogo coletivo em detrimento do individual; as possibilidades coeducativas; e por fim a característica de autoarbitragem (COSTA et al., 2017).

Não sem razão, a Base Nacional Comum Curricular (BNCC) faz referência explicita ao ensino do Ultimate Frisbee na condição de uma das unidades temáticas a ser desenvolvida no âmbito da Educação Física escolar, na direção de fomentar a diversificação dos conteúdos. No interior do documento curricular a modalidade pertence aos esportes de invasão. Todavia, segundo advertem Tomita e Canan (2019), o ensino nas aulas de Educação Física, quando aborda os saberes esportivos, recorre ao modelo hegemônico/tradicional em detrimento a outros saberes e formas de ensino. Se bem que os autores supracitados admitem à existência de esforços pontuais em prol de diversificação de conteúdos da cultura corporal de movimento, por isso ressaltam a necessidade de se ampliar às investigações científicas que desvelem outras proposições e saberes relativos ao universo esportivo, indicando, nessa direção, o Ultimate Frisbee enquanto modalidade esportiva "não tradicional".

Ora, apesar dos autores supracitados aludirem à necessidade de se ampliar às pesquisas que compreendam o Ultimate Frisbee e suas implicações formativas, ao realizarmos uma primeira busca genérica, constatou-se a escassez de literatura científica sobre o mote, um quadro que difere quando se realiza o mesmo exercício investigativo incluindo modalidades esportivas consideradas "tradicionais" ou "hegemônicas", constatação similar a de Oliveira e colaboradores (2018, p. 30), quando destaca "a pouca produção acadêmica nacional sobre as experiências escolares com o Ultimate Frisbee".

Além disso, as mudanças relativas à formação do professor de Educação Física no último decênio, somada à implantação da Base Nacional Comum Curricular (BNCC), na qual 
consta o Ultimate Frisbee enquanto conteúdo a ser ensinado nas aulas de Educação Física muito provavelmente tenha provocado a imprescindibilidade de investigações cujos resultados busquem responder às novas demandas formativas, inclusive no que diz respeito aos desafios para o ensino dessa prática corporal esportiva.

Pois bem, cientes do quadro exposto e das idiossincrasias que a expressão esportiva em questão evoca, resolveu-se empreender um estudo de revisão de literatura sistemática, no qual foram mapeados artigos publicados em periódicos nacionais, dedicados ao entendimento do Frisbee e de suas implicações formativas. Para tanto, realizou-se uma pesquisa qualiquantitativa, cotejando as produções realizadas no decênio de 2009 a 2019, a fim de descobrir o que tem sido produzido quanto a essa prática corporal, e, quem sabe, evidenciar possíveis correlações e implicações para a Educação Física escolar, de maneira que possa lançar rebento em relação ao trabalho pedagógico docente, no que se refere ao Frisbee. A próxima seção descreve os procedimentos metodológicos que nortearam a pesquisa.

\section{METODOLOGIA}

No entendimento de Pires e colaboradores (2017) as investigações de revisão sistemática promovem o avanço do conhecimento em determinado tema e, ao mesmo tempo, permitem a construção da base teórica para outras investigações. Alinhados a esse entendimento Mancini e Sampaio (2007), interpretam que pesquisas que sintetizam a informação científica produzida podem contribuir para o desenvolvimento científico. Segundo as autoras supracitadas, há diferentes tipos de estudos de revisão e cada um deles segue uma metodologia específica. Dentre eles, inserem-se os estudos de revisão sistemática de literatura (científica), cuja metodologia se estrutura sob uma padronização, na qual os procedimentos de busca, seleção e análise são delineadas e claramente definidas, permitindo apreciação da qualidade das pesquisas e da validade das conclusões realizadas.

Com base nessas premissas e organização analítica, empreendeu-se um estudo de revisão de literatura sistemática, no qual foram mapeados artigos publicados em periódicos nacionais, dedicamos ao entendimento do Frisbee e suas implicações formativas. A pesquisa teve duração de seis meses, contando com a participação de quatro pesquisadores de duas Instituições de Ensino Superior (IES) diferentes, sendo dois atuantes e os outros consultivos. 
Para tanto, realizou-se uma investigação sob perspectiva qualiquantitativa, visando uma metodologia mista, na qual haja "combinação pragmática entre pesquisa qualitativa e quantitativa, o que deverá pôr um fim às guerras de paradigmas de tempos mais remotos" (FLICK, 2009, p. 40). A abordagem mista foi adotada nesta investigação por possibilitar mais evidências, do que a pesquisa qualitativa ou quantitativa separadamente, cujos pesquisadores têm a oportunidade de usar diferentes ferramentas para realizar a coleta de dados, não se limitando a apenas instrumentos vinculados a uma vertente de pesquisa seja ela qualitativa ou quantitativa (CRESWEEL; CLARCK, 2013). A esse respeito, Sampiere, Collado e Lúcio (2013, p. 550) comentam:

[...] os métodos mistos representam um conjunto de processos sistemáticos e críticos de pesquisa e implicam a coleta e a análise de dados qualitativos e quantitativos, assim como sua integração e discussão conjunta, para realizar inferências como produto de toda a informação coletada (metainferências) e conseguir um maior entendimento do fenômeno em estudo).

À face disso, no plano quantitativo o estudo emprega a quantificação das produções científicas em formato de artigo, no interstício temporal (2009-2019), que versem sobre o Frisbee. No que se refere à abordagem qualitativa faz uso da análise de conteúdo, tanto para elaboração de categorias - erigidas após o exame dos artigos cotejados - quanto para estabelecer ilações acerca do que tem sido produzido em relação a essa prática corporal esportiva (BARDIN, 2009). Além do mais, indicar (possíveis) correlações e implicações para o ensino desse esporte no interior da Educação Física escolar.

Na qualidade de procedimento analítico para realizar o "balanço de produção", empregou-se uma adaptação da ficha proposta por Kofinas e Saur-Amaral (2008), pela qual se orientou o processo investigativo, permitindo, com isso, a construção dos objetivos do estudo, dos descritores utilizados, bem como os critérios de inclusão e de exclusão dos artigos analisados. A mesma pode ser observada a seguir.

Quadro 1 - Ficha contendo os critérios empregados na pesquisa

\begin{tabular}{|c|l|}
\hline \multicolumn{1}{|c|}{ CONTEÚDO } & \multicolumn{1}{|c|}{ EXPLICAÇÃO } \\
\hline Objetivo da Pesquisa & $\begin{array}{l}\text { Mapear os estudos publicados a respeito do frisbee, procurando } \\
\text { identificar o que se tem produzido em formato de artigo em relação ao } \\
\text { tema. }\end{array}$ \\
\hline $\begin{array}{c}\text { Equação de pesquisa a } \\
\text { experimentar }\end{array}$ & $\begin{array}{l}\text { Frisbee; } \\
\text { Esporte. }\end{array}$ \\
\hline Âmbito da Pesquisa & $\begin{array}{l}\text { A investigação examinou periódicos nacionais com estratificação: A1, A2, } \\
\text { B1, B2, B3, B4, B5 e C, ou seja, analisou todas as classificações. }\end{array}$ \\
\hline Critérios de inclusão & $\begin{array}{l}\text { Foram verificados apenas artigos publicados em periódicos nacionais; } \\
\text { Alocados à subárea da Educação Física; }\end{array}$ \\
\hline
\end{tabular}




\begin{tabular}{|l|l|}
\hline & $\begin{array}{l}\text { Publicados no interstício de tempo de } 2009 \text { a 2019; } \\
\text { Apresentar no título, ou no resumo as equações definidas para pesquisa; } \\
\text { E por fim, os artigos dever-se-iam estar escritos em português, inglês ou } \\
\text { espanhol. }\end{array}$ \\
\hline \multirow{3}{*}{ Critérios de exclusão } & $\begin{array}{l}\text { Artigos sem resumo, ou sem acesso ao texto integral; } \\
\text { Textos sem acesso online e livre (lê-se gratuito); } \\
\text { Artigos publicados em outros idiomas, afora o português, inglês ou } \\
\text { espanhol; } \\
\text { Foram desconsiderados artigos cujo teor central não se dedicava ao } \\
\text { frisbee, ou apenas citavam-no de modo genérico semelhantemente a } \\
\text { outros esportes. }\end{array}$ \\
\hline
\end{tabular}

Fonte: Adaptado da proposta de Kofinas e Saur-Amaral (2008).

Em relação à delimitação do intervalo de tempo (entre 2009 e 2019) para a busca dos estudos, numa primeira busca genérica, constatou-se a ausência de estudos de revisão de literatura cujo mote central se dedicasse exclusivamente ao Frisbee, diferentemente de outras modalidades esportivas consideradas "tradicionais" ou "hegemônicas", a exemplo do voleibol, o qual conduziu Impolceltto e Darido (2016) a realizarem uma pesquisa caracterizada de "estado da arte", dado à ampla produção concernente ao tema, veiculada em diferentes espaços científicos. Interesse ainda mais frequente e consolidado quando se trata do futebol, basta ver (FATT et al., 2016; RIBEIRO; MEZQUITA; VECCHIO, 2013; TEIXEIRA; CAMINHA, 2013; FORTES; CONRADO, 2012).

De igual modo, conjecturou-se que a consolidação da Pedagogia do Esporte na última década - enquanto campo de investigação no interior das ciências do esporte - muito provavelmente tenha fomentado avanços significativos em relação às reflexões e produções relativas ao esporte, suscitando, com isso, estudos relativos ao Ultimate Frisbee, afora o fato de se tratar de um conteúdo relativamente recente no cenário nacional, por efeito pouco difundido, que, por sua vez, suscita curiosidades epistemológicas (REVERDITO; SCAGLIA; MONTAGNER, 2013). Trata-se de uma constatação alinhada ao entendimento de Oliveira e colaboradores (2018, p. 30), ao advertir que "a pouca produção acadêmica nacional sobre as experiências escolares com o Ultimate Frisbee deve servir como estímulo para o desenvolvimento de estudos aplicados".

Além disso, considerou-se que as mudanças relativas à formação do professor de Educação Física no decênio em questão, movimentada e impulsionada pela normatização dos cursos de bacharelado e licenciatura (Brasil, 2002; 2004), somada as Diretrizes Curriculares Nacionais para a Formação Inicial em Nível Superior de Professores para a Educação Básica que têm como referência a implantação da Base Nacional Comum Curricular 
(BNCC) da Educação Básica, instituída pelas Resoluções CNE/CP n 2/2017 e CNE/CP nº 4/2018 (Brasil, 2017), na qual há referência explicita ao ensino do Ultimate Frisbee, tenham provocado a imprescindibilidade de investigações, que busquem responder às novas demandas formativas, até mesmo em relação ao ensino de práticas corporais esportivas "não convencionais". Sendo assim, a "implementação" e consolidação de tais mudanças marcam o período em questão, razão pela qual se definiu a temporalidade da investigação.

Pois bem, para acessar as produções houve caminho analítico, inicialmente se recorreu a Plataforma Sucupira, na qual constam as informações referentes à classificação das revistas usadas pelos programas de pós-graduação. A subdivisão pela qual os periódicos são estratificados, organiza-se da seguinte maneira: A1, A2, B1, B2, B3, B4, B5 e C como um indicativo de qualidade, sendo o mais alto (A1) ao menor (C). As informações mais recentes desta plataforma são as classificações de periódicos que compreendem o quadriênio de 2013 a 2016, em razão disso foi selecionado para consecução do estudo. Em seguida se prosseguiu com o preenchimento da área de avaliação, que para fins desta investigação se restringiu à subárea da Educação Física.

Como resultado a plataforma gerou uma planilha (documento do Microsoft Excel) contendo a listagem de periódicos da Educação Física, com o ISSN tanto impresso quanto eletrônico, o nome dos veículos e sua qualificação com seu respectivo estrato. Neste referido documento, estão os veículos nacionais e internacionais perfazendo 2218 títulos.

Empós o emprego dos critérios analíticos já descritos restaram 389 periódicos. No entanto quando se empregou o último critério de exclusão eliminando revistas cujo foco e escopo não dialogassem especificamente com a Educação Física, visto que a Área 21 congrega quatro subáreas de atuação acadêmica e profissional, contabilizou-se um total de 52 revistas da subárea da Educação Física. Em posse dessa relação iniciou-se a procura de artigos relacionados à temática atinente ao estudo. Com efeito, examinamos as revistas eletrônicas de acesso gratuito, aplicando os critérios de inclusão e exclusão contidos no quadro supracitado. No que se refere à equação de pesquisa, ou melhor, os descritores empregados na ferramenta de busca foram: Frisbee e Esporte, tendo sido suprimido o termo Ultimate. Além da averiguação a partir dos descritores, realizou-se uma apreciação minuciosa em cada uma das edições dos 52 periódicos resultantes da triagem anterior, com o propósito de ratificar os resultados, analisando, por sua vez, os resumos, títulos, descritores e em alguns casos de ambiguidade epistemológica, todo o texto fora apreciado. Os artigos encontrados 
concernentes ao Ultimate Frisbee foram nomeados, datados com o respectivo ano de publicação e organizados/arquivados no interior de pastas no computador, discriminadas de acordo com a denominação da revista a qual pertence.

Os procedimentos de análise de dados se iniciaram por intermédio da leitura das produções científicas encontradas, concomitante fez-se uma síntese dos elementos mais relevantes contidos nos resumos, títulos, descritores e em alguns casos em todo o texto, de maneira que subsidiasse a posterior construção de categorias de análises, a partir de um processo indutivo, decorrente de diversas leituras e releituras, procurando agrupar temas mais recorrentes. Como resultado disso, formulou-se categorias de análise sob uma perspectiva de homogeneidade interna, heterogeneidade externa, inclusividade e plausividade proposta por Lüdke e André (1986), somado a ideia de análise inferencial apregoada por (BARDIN, 2009). Essa organização analítica dos dados qualitativos adicionouse à análise dos dados quantitativos. Os resultados e as discussões são explanados de agora em diante.

\section{RESULTADOS E DISCUSSÃO}

Conforme exposto antes, após o delineamento e os processos de filtragem chegou-se ao total de 52 periódicos da área da Educação Física, compreendendo todos os níveis de estratificação, sendo realizada uma primeira análise em relação à distribuição das revistas no que diz respeito às estratificações. Evidenciou-se a predominância de revistas da subárea na classificação B4, contabilizando 20 revistas, seguida do qualis B5 o qual perfez 13, depois houve uma igualdade entre os agrupamentos B1 e B2, somando 6 ambos periódicos, seguidas do qualis B3 com 5 revistas e o qualis A2 com apenas 2. Destaca-se que não foram localizadas revistas classificadas em A1 e C. Pondera-se que a ausência de estudos na subdivisão $A 1$, justifica-se em decorrência de não haver periódicos nacionais na área 21 com essa estratificação. O conjunto de dados pode ser observado na tabela a seguir.

Tabela 1 - Distribuição das Revistas por Qualis

\begin{tabular}{cccc}
\hline \multirow{2}{*}{ QUALIS } & \multicolumn{3}{c}{ EDUCAÇÃO FíSICA } \\
\cline { 2 - 4 } & $\mathrm{N}$ & $\%$ \\
\hline A1 & 0 & 0 \\
A2 & 2 & 3,8 \\
B1 & 6 & 11,5 \\
B2 & 6 & 11,5
\end{tabular}




\begin{tabular}{ccc} 
B3 & 5 & 9,6 \\
B4 & 20 & 38,5 \\
B5 & 13 & 25 \\
C & 0 & 0 \\
\hline TOTAL & 52 & 100 \\
\hline
\end{tabular}

Fonte: construção dos autores.

A título de explicação, quando se refere ao termo estratificação, via de regra, conhecida como Qualis, trata-se de um sistema de classificação da produção científica dos programas de pós-graduação, referente à publicação de artigos em periódicos científicos. Seu objetivo consiste em analisar e consequentemente avaliar a qualidade da produção científica. A classificação ocorre sob análise de comitês atinentes a cada área de avaliação, valendo-se de critérios pré-definidos (CAPES, 2009).

Para o indicativo de qualidade, organizam-se os periódicos em $A 1$, sendo este nível o mais elevado e subsequentemente por A2; B1; B2; B3; B4; B5 e C - com peso zero. Os periódicos relacionados à Educação Física estarão organizados na área 21, coexistindo com a Fisioterapia, a Terapia Ocupacional e a Fonoaudiologia. A Diretoria de avaliação determina que "o percentual de periódicos dos estratos A1 deve ser inferior ao percentual de periódicos em estratos nos periódicos A2 (A1<A2) e que a soma de ambos seja igual ou inferior a 25\%. O percentual de periódicos que povoam os estratos A1, A2 e B1 são inferiores a 50\%" (CAPES, 2013, p. 22). Fato que, corrobora os resultados encontrados neste estudo, ao constatar restrito número de periódicos nos três maiores níveis de estratificação $(A 1, A 2$ e B1), cuja soma resultou em apenas 8 revistas, do total de 52 cotejados.

Constatou-se a maior concentração de periódicos nas classificações (B2; B3; B4; B5), correspondendo a 44 periódicos, o que engendra um desafio para propagação e qualificação das produções científicas na subárea em questão, apesar de termos consciência de que nem sempre o fator de impacto e a estratificação traduzem a qualidade de uma produção. Ademais, as revistas com estratificação A, são em sua maioria internacionais, priorizando a língua estrangeira moderna (inglês) com ênfase na área da ciência médica, fatores esses que obliteram a publicação de conteúdo de outra natureza epistemológica, além do entrave do idioma para autores brasileiros de modo geral, à semelhança do que advertiu Job (2009, p. 16), "critérios incoerentes para o desenvolvimento da ciência brasileira, uma vez que, o autor local concorre com milhares de outros, de outros países, escrevendo no 
idioma que não é o seu, mas será pouco lido no seu próprio país". Além das altas taxas cobradas para veicular conhecimento no interior dos periódicos internacionais.

Pois bem, até este ponto, procurou-se expor a dimensão quantitativa mais ampla, de maneira a conferir uma espécie de visão panorâmica do quadro numérico, ao passo que tal cenário revelasse, por efeito, as investigações relativas ao Ultimate Frisbee. Após o cotejamento, de acordo com os critérios adotados no estudo, constatou-se 4 artigos, sendo considerados apenas 3, já que 1 não correspondia ao contexto, dado que o eixo central da produção versa a respeito da predominância das modalidades tradicionais em detrimento das não tradicionais, em aulas de Educação Física Escolar em um município paranaense. $\mathrm{Na}$ mesma, há apenas uma singela alusão ao Frisbee enquanto modalidade não tradicional (TOMITA; CANAN, 2019).

Analisando os artigos encontrados, tem-se o seguinte quadro: 1 pertence ao qualis B2, enquanto os outros 2 pertencem ao estrato B5. A descrição detalhada da autoria, revistas e estratificação podem ser conferidas no quadro de agora em diante.

Quadro 2 - Descrição detalhada dos artigos examinados com base nos critérios da pesquisa

\begin{tabular}{|c|l|c|c|c|}
\hline $\begin{array}{c}\text { Autor(es)/An } \\
\text { o }\end{array}$ & \multicolumn{1}{c|}{ Título } & Revista & Qualis & Quantidade \\
\hline $\begin{array}{c}\text { COSTA e } \\
\text { colaboradores } \\
\text { (2017) }\end{array}$ & $\begin{array}{l}\text { Perfil e motivações de praticantes de } \\
\text { ultimate frisbee na universidade de } \\
\text { Brasília }\end{array}$ & $\begin{array}{c}\text { CADERNOS DE } \\
\text { FORMAÇÃO - RBCE }\end{array}$ & B5 & 1 \\
\hline $\begin{array}{c}\text { OLIVEIRA e } \\
\text { colaboradores } \\
\text { (2018) }\end{array}$ & $\begin{array}{l}\text { Sistematização do ultimate frisbee } \\
\text { para Educação Física }\end{array}$ & $\begin{array}{c}\text { CADERNOS DE } \\
\text { FORMAÇÃO - RBCE }\end{array}$ & B5 & 1 \\
\hline $\begin{array}{c}\text { SILVEIRA e } \\
\text { DIAS (2019) }\end{array}$ & $\begin{array}{l}\text { Repensando as relações de gênero } \\
\text { nas vivências do ultimate frisbee na } \\
\text { escola }\end{array}$ & $\begin{array}{c}\text { MOTRIVIVÊNCIA } \\
\text { (FLORIANÓPOLIS) }\end{array}$ & B2 & 1 \\
\hline Total & & & 3 \\
\hline
\end{tabular}

Fonte: construção dos autores.

Um dos possíveis fatores que pode explicar a escassez de artigos sobre o Ultimate Frisbee em periódicos nacionais se relaciona com sua recente inserção no Brasil, mais especificamente no final da década de 1980. Se porventura estabelecêssemos uma relação histórica comparativa com o futebol - a título de mera ilustração -, notar-se-ia prontamente o desconhecimento e a pouca visibilidade que desfruta essa prática corporal historicamente situado, razão pela qual, Amoroso e Varregoso (2014), interpretaram se tratar 
de uma prática em ascensão. O que por sua vez, ratifica a demanda por investigações, consoante a conclusão do estudo de (PUCCINELLI, 2006).

Conjectura-se, além disso, que, a questão do parco reconhecimento tenha relação com o não pertencimento do Ultimate Frisbee ao inventário de "tradições esportivas" historicamente aceitas e disseminadas no país, conforme ponderou Paes (1996), ao observar que os principais conteúdos das aulas de Educação Física são os esportes coletivos, considerados tradicionais (handebol, voleibol, basquetebol e futebol). Na prática, esse fato incide na constituição de uma representação social, que por sua vez oblitera o interesse por outros saberes esportivos, até mesmo científico, já que a ciência é uma prática social e sobre ela pairam idealizações e injunções. Trata-se de uma ilação, ao que parece plausível, haja vista o reduzido número de produções e a incidência majoritária dos artigos em classificação B5, considerada com menor grau de impacto e valoração.

Para analisar os 3 artigos encontrados pela pesquisa e formular categorias de análises, empregou-se os pressupostos anotados por Lüdke e André (1986), somado ao princípio de análise inferencial proposto por (BARDIN, 2009), tal qual já exprimimos na seção anterior, sendo pertinente reiterar. Assentado nisso, instituiu-se três categorias de análise, a saber: 1) Participação; 2) Sistematização Pedagógica; 3) Gênero. A distribuição quantitativa das categorias e seus respectivos anos de publicação constam na tabela doravante.

Tabela 2 - Número absoluto de artigos distribuídos por categoria de análise e ano de publicação

\begin{tabular}{cccc}
\hline CATEGORIA DE ANÁLISE & REVISTA & ANO DE PUBLICAÇÃo & TOTAL \\
\hline Participação & Cadernos de Formação RBCE & 2017 & 1 \\
Sistematização Pedagógica & Cadernos de Formação RBCE & 2018 & 1 \\
Gênero & Motrivivência & 2019 & 1 \\
\hline
\end{tabular}

Fonte: construção dos autores.

Em linhas gerais, nota-se com base nas informações presentes na tabela que, as produções brasileiras que versam sobre Ultimate Frisbee correspondem ao período cuja 
tramitação da BNCC - à vista do fato de que o documento apresentar versões preliminares, tendo em 2015 a primeira, a segunda em 2016 e a terceira no ano ulterior - homologada em 2017, ao menos na proposta correspondente às etapas da Educação Infantil e Ensino Fundamental (BRASIL, 2017). Conjectura-se que não se trate de um acontecimento fortuito, uma vez que o documento passa a nortear os currículos da educação básica, no qual consta a referência à prática corporal, como já exposto antes, com efeito, tem-se uma maior visibilidade da modalidade principalmente em relação aos professores, que buscam aporte teórico para organização pedagógica das aulas de Educação Física. Ainda no plano mais geral, observa-se uma tendência de aumento no somatório das produções, a julgar o decênio cotejado, apesar da quantidade equânime dos últimos três anos (lê-se 2017, 2018 e 2019).

Na direção de aprofundar e ampliar às discussões relativas aos artigos localizados por este estudo, assim como evidenciar aspectos específicos e relevantes, discutir-se-á cada um deles no interior das categorias de análise em que foram alocados, deste ponto em diante.

\section{Participação}

Trata-se de uma categoria de análise cujo teor debate a conexão entre a adesão e participação dos adeptos à prática do Ultimate Frisbee. Nela se encontra o estudo realizado por Costa e colaboradores (2017), o qual analisou os aspectos que motivaram os alunos da Faculdade de Educação Física da Universidade de Brasília (UnB) a participar da disciplina intitulada: Prática Desportiva (PD), no interior da qual se desenvolveu o ensino do Ultimate Frisbee. Segundo os autores, a manifestação esportiva em questão apresenta expressivo potencial educativo.

A referida atividade curricular, oferecida semestralmente na UnB, condicionada à disponibilidade dos professores, "recebe alunos de toda a instituição, oferecendo créditos de ensino, aproximando-os da prática regular de exercícios físicos, da promoção e da manutenção da saúde, além de integrar os estudantes dos diferentes cursos da UnB". (COSTA et al., 2017, p. 86).

A justificativa da qual se vale a disciplina, para ancorar sua presença na matriz curricular, parece genérica e demasiadamente ampla, em especial por ser ofertada em um curso de formação profissional. Cabe aqui, uma pequena digressão, de certo modo são 
discursos que se alinham aos argumentos empregados para "aportarem" a Educação Física na qualidade de componente curricular escolar, geralmente genérico, efetivamente pouco convincente. Voltando, a proposta da PD lembra, inclusive, a perspectiva de Prática Esportiva, alinhada à orientação normativa dos currículos do ensino superior brasileiro, sob o decreto $\mathrm{n}$. 705 de 25 de julho de 1969, tendo o mesmo recebido, ainda mais força durante a década de 1970, quando o desporto universitário canalizava, em parte, a atenção dos estudantes envolvidos com a prática desportiva. Cenário que foi sendo modificado gradativamente e resultou na retirada da obrigatoriedade da Educação Física na educação superior - a exceção dos cursos de graduação da própria área - com a promulgação da LDB de 1996, quando a obrigatoriedade fora mantida apenas no ensino fundamental e médio (CASTELLANI FILHO, 1998).

Quanto ao estudo de fato, os autores supracitados objetivaram compreender os principais interesses de 50 voluntários, sendo 32 homens e 18 mulheres ao participarem da PD que propõe o Ultimate Frisbee. Para a consecução do material empírico, utilizou-se à observação participante e o emprego de um questionário e os registros em um diário de campo. As respostas do questionário foram agrupadas em dois blocos de motivos para participação na PD de Ultimate Frisbee, sendo eles: motivos intrínsecos ao jogo e extrínsecos. Os resultados demonstraram que 117 respostas assinalaram para motivos intrínsecos ao jogo como: interesse, curiosidade e conhecer novas pessoas. Já em relação aos motivos extrínsecos, tais como: necessidade de créditos, falta de vaga em outra PD e convite de conhecidos, totalizou 100 respostas.

Há, portanto, certo equilíbrio entre os dois conjuntos de respostas. Para Costa e colaboradores (2017, p. 89) "O equilíbrio aproximado permite inferir que (1) no caso da leve prevalência de motivos extrínsecos, a relevância na oferta de modalidades inovadoras pode trazer expectativas novas e mais pessoas para a atividade física". E complementa "(2) no caso da significativa presença de motivos extrínsecos, [deve-se] refletir que a conjuntura envolta na escolha é fundamental para que novos e regulares praticantes façam as atividades". Um aspecto intrigante das ilações apresentadas se refere à acepção da prática do Ultimate Frisbee como atividade física, que a despeito de sê-la - como toda e qualquer ação humana, já que existimos corporalmente -, associá-la à ideia de promoção e da manutenção da saúde nos parece no mínimo questionável, tendo em vista as variáveis que envolvem o conceito de saúde. Além disso, no que diz respeito à prevalência dos aspectos intrínsecos, em 
desvantagem às questões extrínsecas, bastaria um entendimento mais elaborado a respeito da Teoria do Jogo, para saber que se trata de uma evidência a priori anunciada (CARNEIRO, 2017).

De todo modo o estudo traz indicativos relevantes sobre o interesse na prática do Ultimate Frisbee, de igual modo reforça a relevância do ensino relativo a esse saber, um avanço, portanto, haja vista o desconhecimento e a escassez de produções a respeito do tema. Vejamos na sequência a próxima categoria de análise.

\section{Sistematização Pedagógica}

Refere-se a uma categoria que congregue produções sobre a organização pedagógica sistematizada relativa ao Ultimate Frisbee, isso equivale a dizer que ela reúne artigos - no caso como houve apenas um estudo, aplica-se artigo - que se dedicaram a pensar a planificação do trabalho pedagógico em relação ao tema em questão.

No interior da Sistematização Pedagógica foi alocada a pesquisa realizada por Oliveira e colaboradores (2018), cujo objetivo consistiu em pensar a sistematização do ensino Ultimate Frisbee, a fim de desenvolvê-lo como conteúdo nas aulas de Educação Física Escolar. O estudo realçou as prerrogativas formativas - guardada as devidas proporções e contexto, trata-se de uma perspectiva análoga a de Costa e colaboradores (2017), a qual se arrazoou na categoria anterior - desse saber esportivo, com ênfase na oportunidade de autoarbitragem, cujos efeitos, segundo os autores "estimula, de maneira autônoma, a resolução de conflitos por meio do diálogo, o reconhecimento de comportamentos indevidos, tanto seus quanto dos seus companheiros, de maneira justa e sem imposições". (OLIVEIRA et al., 2018, p. 25).

Pari passu detectaram a escassez de aporte teórico/metodológico em língua vernácula, de maneira que "a pouca produção acadêmica nacional sobre as experiências escolares com o Ultimate Frisbee deve servir como estímulo para o desenvolvimento de estudos aplicados para compreender mais sobre os interesses dos alunos, a sistematização de conteúdos e a avaliação da ação pedagógica docente" (OLIVEIRA et al., 2018, p. 30). A inópia de produção da qual os pesquisadores se referem, ratifica-se de igual modo em nossa investigação, haja vista termos encontrado em um decênio apenas três artigos, o que de certo modo demonstra a relevância de nossa pesquisa. 
O estudo de Oliveira e colaboradores (2018) correspondeu a uma pesquisa-ação, desenvolvida em um Centro de Ensino Fundamental do Distrito Federal. Participaram da proposta de inserção do Ultimate Frisbee, como conteúdo da Educação Física Escolar, aproximadamente 43 alunos de ambos os sexos, que estavam cursando o oitavo ano, divididos em duas turmas distintas. Foram realizadas pela primeira autora da pesquisa, 4 aulas organizadas em alternância entre teoria e prática, com objetivo de trabalhar aspectos técnicos e táticos básicos do esporte, "dentro de uma perspectiva de ensino baseada no Ensinar para a Compreensão" (OLIVEIRA et al., 2018, p. 24).

Segundo eles (lê-se os autores), ao longo da sistematização foi notória a evolução dos alunos em relação ao primeiro contato com o disco e a partida realizada no último encontro, não houve melhorias apenas técnicas e táticas, mas avanços no que diz respeito ao diálogo e autonomia entre os participantes, sendo observável com base no pedido de faltas e na solução de problemas. Houve, no entanto, maior resistência pela turma $B$ em realizar as atividades, devido à preferência pelo futebol - outro indicador da hegemonia dos esportes coletivos tradicionais, da qual já se arrazoou antes. Outro limitante observado se relaciona à presença dos termos em inglês presente na estrutura organizacional da modalidade, muitos alunos apresentaram dificuldade em pronunciá-los, um obstáculo que suscita abertura para pensar à interdisciplinaridade. A propósito, um ponto controverso no espaço escolar, muito apregoado, conquanto raramente aprofundado, deveras pouco desenvolvido (FAZENDA, 1994).

Um questionário de avaliação foi o instrumento aplicado junto aos alunos, na tentativa de extrair a impressão dos mesmos sobre a unidade didática relativa ao Ultimate Frisbee. As respostas exprimem um teor positivo, dado que $79,07 \%$ dos alunos consideram ótimas ou boas suas vivencias referentes a essa manifestação esportiva na escola. Consoante aos autores, o trabalho pedagógico oportunizou o desenvolvimento da autonomia dos discentes (OLIVEIRA et al., 2018). A despeito de admitirmos as potencialidades formativas advinda do Ultimate Frisbee, parece-nos temerário falar de autonomia. A complexidade de elementos que estão em disputa para o alcance do autogoverno (moral e intelectual) são tantos, que asseverar sua existência em uma intervenção (pedagógica) pontual, temporalmente restrita e sem um exame longitudinal de avaliação, não passe de um mero ardil, quiçá, mais um clichê, dentre tantos que, vez ou outra, eclodem nos discursos 
professorais. No limite, pode-se aceitar que o trabalho pedagógico provocou um espaço que nutriu elementos imprescindíveis para o alcance da autonomia.

Além disso, deve-se reconhecer que o desenvolvimento de uma unidade didática, no interstício de quatro aulas - considerando as três dimensões do conteúdo (conceitual/factual, procedimental e atitudinal), somado a necessidade de uma avaliação diagnóstica, para abalizar à planificação do ensino, a preparação e desenvolvimento dos recursos auxiliares e as decisões metodológicas, cujos efeitos conduziriam a um processo de aferir uma experiência de aprendizagem (avaliação) - origina certa desconfiança, dado a sua brevidade, já que a distribuição temporal para planificação e o desenvolvimento de um conteúdo, figura como uma variável importante para o êxito pedagógico. Ademais o próprio instrumento eleito como forma de avaliação, apresenta limites - considerando as exigências que compreendem uma pesquisa-ação - o que por sua vez, acendeu nossas dúvidas. Apesar disso, as contribuições da pesquisa são patentes, seja em decorrência da visibilidade que engendra a prática corporal, ou mesmo em razão de desenvolvê-la no interior da instituição escolar, a partir de uma sistematização de ensino, lançando luz ao trabalho pedagógico para àqueles que pretendem abordar o mote. Na continuidade exporemos a última categoria de análise.

\section{Gênero}

Diz respeito a uma categoria que reúne produções relativas ao Ultimate Frisbee e a questão de gênero. Quanto ao conceito de gênero aqui compreendido, trata-se de uma categoria relacional entre mulheres e homens que, ao rejeitar o sentido do determinismo biológico, passa a envolver valores construídos socialmente ao longo da história. Ao passo que ele, o gênero, torna-se "a criação inteiramente social das ideias sobre os papéis próprios aos homens e às mulheres. Ele é, [portanto], segundo essa definição, uma categoria social imposta sobre um corpo sexuado" (SCOTT, 1995, p. 75).

No inteiro dessa última categoria analítica, encontra-se o estudo de Silveira e Dias (2019), realizado em uma escola da Rede Municipal de Ensino de Natal/RN. Trata-se de uma pesquisa fomentada a partir do projeto intitulado: "Ultimate Frisbee - vivências e reflexões táticas utilizando recursos midiáticos nas aulas de Educação Física", no qual o objetivo consistiu em refletir sobre as vivências táticas da modalidade, com base em imagens 
midiáticas produzidas pelos próprios alunos. Os recursos midiáticos foram disponibilizados pela Universidade Federal do Rio Grande do Norte.

As autoras esclarecem que o contato com Ultimate Frisbee advém em razão de sua presença na BNCC, já que se deparam com o mote em um espaço de formação continuada, no qual se debatia a nova proposta curricular. Notemos, com isso, a relevância de um documento oficial e suas implicações curriculares, tanto para um dado conteúdo quanto para uma área de conhecimento. Trata-se de uma constatação que reforça nossa inferência contida no início desta seção, quando se mencionou que o aumento da produção científica, retratada em forma de artigo, sobre Ultimate Frisbee corresponde aos últimos três anos, coincidindo com o ano da homologação da Base Nacional Comum Curricular (BNCC), em 2017 (Brasil, 2017), com efeito, tem-se uma maior visibilidade da modalidade, visto que os professores buscam aporte teórico para organização do trabalho pedagógico, realçando outro aspecto já destacado.

Ao longo do estudo as autoras supracitadas discorrem a respeito do caráter formativo e educativo que o Ultimate Frisbee - algo também admitido nas duas investigações debatidas nas seções precedentes. Participaram da pesquisa aprendentes que frequentavam duas turmas mistas de $5^{\circ}$ ano, denominadas $A$ e $B$, do Ensino Fundamental, com idade variando entre 9 e 13 anos. Durante as aulas as turmas eram organizadas em equipes mistas, no entanto, a primeira turma possuía um número inferior de meninas em relação aos meninos o que contribuía para a dominância da posse do disco por parte deles, não havendo compartilhamento do mesmo com as meninas, excetuando daquelas que eram consideradas mais habilidosas. Houve, portanto uma clara exclusão das meninas, fato observado por Silveira e Dias (2019, p. 7), ao comentarem a respeito explicam, "percebemos aqui uma problemática para refletir: a histórica exclusão feminina no âmbito público, em especial nas práticas corporais esportivas".

Já em relação à outra turma havia uma divisão sexual equiparada, o que incidiu numa participação maior das meninas na prática, portanto, houve o compartilhamento do disco, ainda assim existiram atitudes intimidadoras dos meninos frente às meninas, com gritos, empurrões e até de violência para se imporem diante delas. À face disso, as pesquisadoras Silveira e Dias (2019) se despertam para refletirem sobre duas problemáticas intrinsecamente ligadas, a primeira se refere à naturalização equivocada do comportamento feminino e a segunda diz respeito à premissa biológica da/na construção das identidades 
femininas e masculinas, por sua vez hegemônicas, cujos efeitos aprisionam homens e mulheres a padrões predeterminados e altamente excludentes em relação às mulheres. Aparentemente, ao se permitirem tais reflexões se alinham a advertência comentada por Louro (2000, p. 138), ao argumentar que "nossas escolas parecem propor um acordo tácito de silêncio, dissimulação e negação a respeito da sexualidade" no qual estudantes e professoras/es omitem questionamentos, disfarçam curiosidades e inquietações, muitas vezes, por temor a represálias.

Cientes disso, as autoras (re)construíram uma proposta de ensino inclusiva do Ultimate Frisbee, assentada na perspectiva da diversidade e da abertura para rechaçar o contexto social em questão. Como forma de rearranjo das intervenções pedagógica, observando a multiplicidade de masculinidades e feminilidades, as autoras recorreram às rodas de conversa, na direção de fomentarem a conscientização, cujas implicações engendrassem o aumento da participação e inclusão de todos no jogo, para tanto, decidem pela marcação de ponto apenas se todos da equipe participassem do ataque. Porém, a insatisfação das meninas persiste, com isso, outras variáveis foram sendo modificadas, de maneira a promover um ambiente formativo provocador.

Por fim, analisando o trabalho pedagógico realizado, Silveira e Dias (2019) entendem que a relação entre o Ultimate Frisbee e as questões de gênero conferiu a oportunidade para reformulação dos conhecimentos, melhoria na compreensão e construção de novas situações para o exercício da docência, além de construir relações de gêneros mais igualitárias. Contudo, embora reconheçamos o empenho e alargamento das margens formativas das autoras, quando se trata de gênero, uma categoria relacional entre mulheres e homens, construídos socialmente ao longo da história da vida do indivíduo, toda e qualquer afirmação peremptória deve ser evitada, dado que a identidade (de gênero) permanece em construção, nesse sentido, não é possível afirmar que as atividades decorrentes do trabalho pedagógico realizado construíram, nem nos aprendizes, tampouco nas pesquisadoras, relações mais igualitárias, no limite, fomentaram reflexões, cujos efeitos desestabilizaram convicções, o que concordemos já caracteriza um fato desejável e elogiável. Doravante, passaremos as impressões finais cujo estudo nos permitiu elucubrar.

\section{CONSIDERAÇÕES FINAIS}


Os dados erigidos pelo estudo revelaram a existência de quatro produções, no interstício pesquisado, sendo considerados apenas três, já que uma delas não correspondia ao mote central, apenas citou o Frisbee como modalidade não tradicional. Tratou-se de número tímido de artigos encontrados. Conjectura-se que um dos possíveis fatores que pode explicar a escassez de artigos sobre o tema em periódicos nacionais, relacionam-se com sua recente inserção no Brasil, mais especificamente no final da década de 1980. Ademais, tem-se o fato do Ultimate Frisbee não pertencer ao inventário de "tradições esportivas" historicamente aceitas e disseminadas no país, ofuscando, por sua vez, o interesse pelo mote, inclusive científico, uma ilação plausível, a julgar pelo diminuto número de produções e a incidência majoritária dos artigos em classificação B5, considerada com menor grau de impacto e valoração (PAES, 1996).

Os três artigos cotejados pela pesquisa foram agrupando-os em três categorias de análise, a saber: 1) Participação; 2) Sistematização Pedagógica; 3) Gênero, nas quais os mesmos foram examinados e trouxemos à baila aspectos específicos e relevantes de cada um dos estudos, assim como algumas reflexões de ordem provocativa. Grosso modo, o que fica patente a luz de nossa investigação é uma tendência de aumento no somatório das produções, a julgar o decênio cotejado, muito embora tenha havido uma quantidade equitativa nos últimos três anos (lê-se 2017, 2018 e 2019). Fato que coincide temporalmente com o ano da homologação da Base Nacional Comum Curricular (BNCC), um acontecimento que engendrou implicações tanto no que concerne a visibilidade quanto ao interesse a respeito do Ultimate Frisbee (BRASIL, 2017).

Cabe salientar, além disso, que, apesar das informações produzidas e aqui veiculadas serem datadas historicamente, em função da natureza do próprio texto e a pesquisa que ele retrata, ao mesmo tempo confere um olhar panorâmico sobre determinado momento histórico, na tentativa de lançar rebento acerca do fenômeno estudado. Ademais, como modelo heurístico, tal estudo pode representar um ponto de partida para o desenvolvimento de outras pesquisas que considerem critérios de análise diferentes, em que pese o fato de seu limite temporal e o alcance restrito, ao cotejar apenas artigos.

\section{REFERÊNCIAS BIBLIOGRÁFICAS}

BARDIN, Laurence. Análise de conteúdo. 5. ed. Lisboa: Edições 70, 2009. 
BRASIL. Resolução n. 2, de 19 de fevereiro de 2002. Carga Horária dos Cursos de Formação de Professores. Diário Oficial da União, Brasília, 4 mar., Seção 1, p. 9. Oficial da União de 18/1/2002, Seção 1, p. 31, 2002.

BRASIL. Resolução n. 7, de 31 de março de 2004. Diretrizes Curriculares Nacionais dos Cursos de Graduação em Educação Física. Diário Oficial da União, Brasília, 5 abr., Seção 1, p. 18, 2004.

BRASIL. Base Nacional Comum Curricular. Brasília: MEC, 2017. Disponível em: http://basenacionalcomum.mec.gov.br/images/BNC C_20dez_site.pdf. Acesso em: 22 de dezembro de 2019.

BORGES, Robson Machado e colaboradores. Ultimate frisbee. In: GONZÁLEZ, Fernando Jaime; DARIDO, Suraya Cristina; OLIVEIRA, Amauri Aparecido Bássoli de. (Orgs.). Esportes de invasão: basquetebol, futebol, handebol, ultimate frisbe. Maringá, PR: Eduem, 2017.

CARNEIRO, Kleber Tuxen. Por uma memória do jogo: a presença do jogo na infância das décadas de 20 e 30. Curitiba, PR: Appris, 2017.

CASTELLANI FILHO, Lino. Política educacional e educação física. Campinas, SP: Autores Associados, 1998.

COORDENAÇÃO DE APERFEIÇOAMENTO DE PESSOAL DE NÍVEL SUPERIOR - CAPES. Classificação da produção intelectual, 2009. Disponível em: http://www.capes.gov.br /avaliacao/instrumentos-de-apoio/classificacao-da-producao-intelectual. Acesso em: 03 de jun. 2020.

COORDENAÇÃO DE APERFEIÇOAMENTO DE PESSOAL DE NÍVEL SUPERIOR - CAPES. Documento de área e comissão, 2013. Disponível em: https://docs.google.com/viewer ?a =v\&pid=sites\&srcid=Y2FwZXMuZ292LmJyfHRyaWVuYWwtMjAxM3xneDoyODNmNjljODc1 OTRjZTU. Acesso em: 03 de jun. 2020.

COSTA, Felipe Rodrigues da e colaboradores. Perfil e motivações de praticantes de ultimate frisbee na Universidade de Brasília. Cadernos de formação RBCE, v. 8, n. 2, p. 84-94, set. 2017.

COSTA, Felipe Rodrigues da e colaboradores. Leitura pedagógica das regras de ultimate: uma versão em português para uso na iniciação. Brasília, DF: Universidade de Brasília, 2018. Disponível em: https://repositorio.unb.br/handle/10482/33152. Acesso em: 21 set. 2020.

CRESWELL, John W.; CLARK, Vicki L. Plano. Pesquisa de métodos mistos: série métodos de pesquisa. 2. ed. Porto Alegre, RS: Penso, 2013.

FATTA, Giovanni Laporte e colaboradores. Gestão e estrutura organizacional no futebol: uma revisão sistemática. Revista intercontinental de gestão desportiva, 6, jun., 2016. Disponível em: http://www.revista.universo.edu.br/index.php?journal=gestaoesportiva\&page=article\&op =view\&path\%5B\%5D=2333\&path\%5B\%5D=2438. Acesso em: 10 Dez. 2020. 
FAZENDA, Ivani Catarina Arantes. Interdisciplinaridade: história, teoria e pesquisa. Campinas, SP: Papirus, 1994.

FLICK, Uwe. Introdução à pesquisa qualitativa. 3. ed. Porto Alegre, RS: Artmed, 2009.

FORTES, Bruno Silveira; CONRADO, Júlia Martimbianco. Os traços de personalidade dos jogadores de futebol: uma revisão sistemática. Revista da graduação, v. 5, n. 1, 31 mai., 2012.

IMPOLCELTTO, Fernanda Moreto; DARIDO, Suraya Cristina. O "estado da arte" do voleibol e do voleibol na escola. Revista brasileira de ciência e movimento, v. 24, n. 4, p. 175-186, 2016.

KOFINAS, Alexander; SAUR-AMARAL, Irina. 25 years of knowledge creation processes in Pharmaceutical Contemporary Trends. Comportamento organizacional e gestão, v. 14, n. 2 , p. 257-280, 2008.

LOURO, Guacira Lopes. Pedagogias da sexualidade. In: LOURO, Guacira Lopes (Org.). 0 corpo educado: pedagogias da sexualidade. 3. ed. Belo Horizonte, MG: Autêntica, 2008.

LUDKE, Menga; ANDRÉ, Marli Eliza Dalmazo Afonso. Pesquisa em educação: abordagens qualitativas. São Paulo, SP: EPU, 1986.

OLIVEIRA, Erica dos Santos e colaboradores. Sistematização do ultimate frisbee para educação física. Cadernos de formação RBCE, v. 9, p. 20-32, mar., 2018.

PAES, Roberto Rodrigues. Educação física escolar: o esporte como conteúdo pedagógico do ensino fundamental. 1996. 198f. Tese (Doutorado em Educação). Universidade Estadual de Campinas, Campinas, SP, 1996.

REVERDITO, Riller Silva; SCAGLIA, Alcides José; MONTAGNER, Paulo César. Pedagogia do esporte: aspectos conceituais da competição e estudos aplicados. São Paulo: Phorte, 2013.

PIRES, Veruska e colaboradores. Identidade docente e educação física: um estudo de revisão sistemática. Revista portuguesa de educação, v. 30, n. 1, p. 35-60, jun., 2017.

PUCCINELLI, Fernanda Mauro. A construção de consensos dentro de jogos competitivos um estudo de caso: ultimate frisbee. 2006. 59f. Monografia (Licenciatura em Educação Física). Universidade Estadual de Campinas, Campinas, SP, 2006.

RIBEIRO, Yuri; MEZQUITA Luis; VECCHIO, Fabrício Del. Revisão sistemática dos efeitos do futebol recreacional em adultos não atletas. Revista brasileira de atividade física e saúde, v. 18, n. 6, p. 655-668, nov., 2013. 
SAMPAIO, Rosana Ferreira; MANCINI, Marisa Cotta. Estudos de revisão sistemática: um guia para síntese criteriosa da evidência científica. Revista brasileira de fisioterapia, v. 11, n. 1, p. 83-89, fev., 2007.

SAMPIERI, Roberto Hernández; COLLADO, Carlos Fernández; LUCIO, Maria del Pilar Baptista. Metodologia de pesquisa. Porto Alegre, RS: Penso, 2013.

SCOTT, Joan Wallach. Gênero: uma categoria útil de análise histórica. Educação \& realidade, v. 20, n. 2, p. 71-79, jul./ dez., 1995.

SILVEIRA, Ana Aparecida Tavares da; DIAS, Maria Aparecida. Repensando as relações de gênero nas vivências do ultimate frisbee na escola. Motrivivência, v. 31, n. 58, p. 1-15, abr./ jul., 2019.

TEIXEIRA, Fábio Luís Santos; CAMINHA, Iraquitan de Oliveira. Preconceito no futebol feminino brasileiro: uma revisão sistemática. Movimento, v. 19, n. 1, p. 265-287, jan./ mar., 2013.

TOMITA, Andréa Setsuko Fortuna; CANAN, Felipe. A utilização de modalidades esportivas não tradicionais em aulas de educação física escolar. Corpoconsciência, v. 23, n. 2, p. 13-25, mai./ ago., 2019.

\section{Dados da primeira autora:}

Email: angelica.silva2@estudante.ufla.br

Endereço: Departamento de Educação Física (DEF), Campus Universitário da UFLA, Caixa Postal 3037, Lavras, MG, CEP: 37200-900, Brasil.

Recebido em: 23/09/2020

Aprovado em: 12/01/2021

\section{Como citar este artigo:}

SILVA, Angélica de Souza; CARNEIRO, Kleber Tüxen. A produção do conhecimento relativa ao ultimate frisbee no decênio 2009-2019. Corpoconsciência, v. 25, n. 1, p. 1-22, jan./ abr., 2021. 